\title{
Micronutrient intake and food sources in the very old: analysis of the Newcastle 85+ Study
}

\author{
Nuno Mendonça ${ }^{1,2,3}$, Tom R. Hill ${ }^{1,2,3 *}$, Antoneta Granic ${ }^{2,4}$, Karen Davies ${ }^{2,4}$, Joanna Collerton ${ }^{2,4}$, \\ John C. Mathers ${ }^{2,3}$, Mario Siervo ${ }^{2,3}$, Wendy L. Wrieden ${ }^{3,4}$, Chris J. Seal $^{1,3}$, Thomas B. L. Kirkwood ${ }^{2}$, \\ Carol Jagger ${ }^{2,4}$ and Ashley J. Adamson ${ }^{2,3,4}$ \\ ${ }^{1}$ School of Agriculture Food and Rural Development, Newcastle University, Newcastle upon Tyne NE1 7RU, UK \\ ${ }^{2}$ Newcastle University Institute for Ageing, Newcastle University, Newcastle upon Tyne NE2 4AX, UK \\ ${ }^{3}$ Human Nutrition Research Centre, Newcastle University, Newcastle upon Tyne NE2 4HH, UK \\ ${ }^{4}$ Institute of Health and Society, Newcastle University, Newcastle upon Tyne NE4 5PL, UK
}

(Submitted 27 November 2015 - Final revision received 27 May 2016 - Accepted 31 May 2016 - First published online 1 July 2016)

\begin{abstract}
A number of socio-economic, biological and lifestyle characteristics change with advancing age and place very old adults at increased risk of micronutrient deficiencies. The aim of this study was to assess vitamin and mineral intakes and respective food sources in 79385 -year-olds (302 men and 491 women) in the North-East of England, participating in the Newcastle 85+ Study. Micronutrient intakes were estimated using a multiple-pass recall tool $(2 \times 24 \mathrm{~h}$ recalls). Determinants of micronutrient intake were assessed with multinomial logistic regression. Median vitamin D, Ca and Mg intakes were 2.0 (interquartile range (IQR) 1.2-6.5) $\mathrm{g} / \mathrm{d}, 731$ (IQR 554-916) mg/d and 215 (IQR 166-266) mg/d, respectively. Fe intake was 8.7 (IQR $6.7-11.6) \mathrm{mg} / \mathrm{d}$, and Se intake was 39.0 (IQR $27 \cdot 3-55.5) \mu \mathrm{g} / \mathrm{d}$. Cereals and cereal products were the top contributors to intakes of folate (31.5\%), Fe (49.2\%) and Se (46.7\%) and the second highest contributors to intakes of vitamin D (23.8\%), $\mathrm{Ca}(27.5 \%)$ and $\mathrm{K}(15 \cdot 8 \%)$. More than $95 \%(n$ 756) of the participants had vitamin D intakes below the UK's Reference Nutrient Intake $(10 \mu \mathrm{g} / \mathrm{d})$. In all, $>20 \%$ of the participants were below the Lower Reference Nutrient Intake for $\operatorname{Mg}(n 175)$, K $(n$ 238) and Se $(n$ 418) (comparisons with dietary reference values (DRV) do not include supplements). As most DRV are not age specific and have been extrapolated from younger populations, results should be interpreted with caution. Participants with higher education, from higher social class and who were more physically active had more nutrient-dense diets. More studies are needed to inform the development of age-specific DRV for micronutrients for the very old.
\end{abstract}

Key words: Dietary intakes: Vitamins: Minerals: Aged 80 years and over: Newcastle 85+ Study

A number of socio-economic, biological and lifestyle characteristics change with advancing age and place very old adults (those aged 85 years and over) at increased risk of micronutrient deficiencies. For example, 10-30\% of older adults (aged 65 years and over) have atrophic gastritis and hypochlorhydria ${ }^{(1)}$, which reduce secretion of acid-pepsin and intrinsic factor, allowing small-bowel bacterial growth and leading to impaired vitamin $B_{12}$ absorption $^{(2)}$. Although micronutrient malabsorption is not an inherent consequence of ageing, the absorption of $\mathrm{pH}$-dependent vitamins and minerals, such as folate, vitamin $\mathrm{B}_{12}, \mathrm{Ca}, \mathrm{Fe}$ and $\beta$-carotene, might be partially compromised ${ }^{(1,3)}$. Very old adults are also at higher risk of vitamin D deficiency due to reduced skin stores of 7-dehydrocholesterol (provitamin D), renal impairment and reduced renal conversion of its biologically inert to active form (i.e. 25-hydroxyvitamin D to calcitriol), immobility, malnutrition and environmental factors (reviewed in Hill et al. ${ }^{(4)}$ ).
Micronutrient deficiencies may contribute to disability, frailty and impaired physical function in very old adults ${ }^{(5)}$.

In the UK, apart from the Reference Nutrient Intake (RNI) for vitamin $\mathrm{D}$, which sets a dietary reference value (DRV) for people aged 65 years and over, all other DRV for vitamins or minerals apply equally to everyone aged $\geq 50$ years $^{(6)}$. The scarcity of dietary data on very old adults, and lack of evidence on relationships with risk factors and health outcomes, have resulted in DRV based on extrapolations from younger populations $^{(7)}$.

The 1994/1995 National Diet and Nutrition Survey (NDNS) of people aged 65 years and over identified a significant number of older adults with inadequate micronutrient intakes - namely, vitamin $\mathrm{D}, \mathrm{Mg}$ and $\mathrm{K}^{(8)}$. A review of micronutrient intakes across Europe revealed that inadequacy (assessed against the Nordic Nutrition Recommendations, estimated average intake) was

Abbreviations: 24h-MPR, 24-h multiple-pass recall; CCP, cereals and cereal products; DRV, dietary reference value; IQR, interquartile ranges; LRNI, Lower Reference Nutrient Intake; NDNS, National Diet and Nutrition Survey; RNI, Reference Nutrient Intake.

* Corresponding author: T. Hill, email tom.hill@newcastle.ac.uk 
present in more than $20 \%$ of older adults ( $\geq 65$ years) for vitamin $\mathrm{D}$, folate, $\mathrm{Ca}$ and $\mathrm{Se}^{(9)}$. Similarly, a review of noninstitutionalised older adults living in Western countries concluded that at least 30\% were below the estimated average requirement (EAR) for vitamin $\mathrm{D}$, vitamin $\mathrm{B}_{2}, \mathrm{Ca}, \mathrm{Mg}$ and $\mathrm{Se}^{(10)}$.

The aims of this study were to assess daily energy, vitamin and mineral intakes of 85 -year-olds participating in the Newcastle 85+ Study, determine their food sources, compare intakes with the current UK DRV and to explore socio-economic and lifestyle determinants of micronutrient intakes.

\section{Methods}

\section{Newcastle 85+ Study}

The Newcastle $85+$ Study is a longitudinal, population-based study of health trajectories and outcomes of a cohort of 845 very old people ( 85 years old at baseline) born in 1921 (for details visit http://research.ncl.ac.uk/85plus) ${ }^{(11-13)}$. Complete dietary intake data (without protocol violation) were available for 793 participants (302 men and 491 women).

\section{Dietary assessment, micronutrient estimation and supplement use}

Dietary intakes were collected using a 24-h multiple-pass recall (24h-MPR) tool on two distinct occasions ( 1 week apart and on different days of the week) at baseline $(2006 / 2007)$ by trained research nurses and in the participant's usual residence. Food and drink portion sizes were estimated using the Photographic Atlas of Food Portion Sizes ${ }^{(14)}$. All dietary intake data were independently double entered. Any discrepancies were identified, checked against original records and corrected before data analysis. Energy, vitamin and mineral intakes were estimated using McCance and Widdowson's the Composition of Food, 6th edition (used as published) ${ }^{(15)}$ together with a purposedesigned in-house Microsoft Office Access database on the nutrient composition of commonly consumed foods ${ }^{(16)}$. In all, 85 and $90 \%$ of the participants believed that the $24 \mathrm{~h}-\mathrm{MPR}$ reflected their usual food and drink intakes, respectively. Intakes of energy, vitamin $\mathrm{A}, \beta$-carotene, vitamin $\mathrm{B}_{2}$, vitamin $\mathrm{B}_{6}$, folate, vitamin $\mathrm{B}_{12}$, vitamin $\mathrm{E}$, vitamin $\mathrm{C}$, vitamin $\mathrm{D}, \mathrm{Ca}, \mathrm{Fe}, \mathrm{Mg}$, $\mathrm{K}$, Na, Se and $\mathrm{Zn}$ are reported in this article (excluding supplements). Vitamin and mineral densities per $1 \mathrm{MJ}$ of energy were also calculated.

Supplement use was divided into three categories: no supplements, one supplement and two or more supplements. Information on supplement use was limited to type and brand; therefore, micronutrient-containing supplements were assumed to be taken according to the manufacturer's specifications. Supplement users were characterised by supplement type: those taking fish and $n$-3 oil preparations, single mineral/ vitamin preparations, multivitamin and/or multimineral preparations, and other supplements. Micronutrient intakes from all sources (including supplements) and the difference (\%) between micronutrient intakes from dietary sources only (excluding supplements) were determined, but supplements were not included in the main analysis.

\section{Food groups}

Individual foods were coded and allocated to food groups. In brief, individual foods were allocated to fifteen first-level food groups: cereals and cereal products (CCP), milk and milk products, eggs and egg dishes, oils and fat spreads, meat and meat products, fish and fish dishes, vegetables, potatoes, savoury snacks, nuts and seeds, fruits, sugar, preserves and confectionery, non-alcoholic beverages, alcoholic beverages and miscellaneous ${ }^{(16)}$. The average contribution of food groups to vitamin and mineral intakes was reported so that $\geq 90 \%$ of intakes could be explained.

\section{Estimation of misreporting}

The proportion of possible misreporters was calculated using a energy intake:BMR cut-off value of 1.05-2.00 (further details can be found in the study by Mendonça et al. $\left.{ }^{(16)}\right)$. With this cutoff value, $26.3 \%$ were identified as misreporters $(21.6 \%$ as under-reporters and $4.7 \%$ as over-reporters). Possible misreporters have not been excluded from the analysis because of the uncertainty surrounding this estimate and the small differences observed between excluding and not excluding misreporters ${ }^{(16)}$. Further, in $5 \%$ of the participants ( $n$ 42), the proxy was the only respondent.

\section{Socio-economic, health and lifestyle factors}

Apart from supplement use, details on other socio-economic and lifestyle variables have been previously published ${ }^{(11)}$ and commented on in the companion paper: 'Macronutrient intake and food sources in the very old: analysis of the Newcastle $85+$ Study $^{,(16)}$. Participants were classified according to housing: standard, sheltered or institutional housing. Further, participants were characterised as living alone, with spouse or with others, years of full-time education (categorised as <9/10-11/ and $>12$ years) and social class according to the National Statistics Socio-Economic Classification (NS-SEC) three-class scheme ${ }^{(17)}$. Participants were also categorised into those with low (scores 0-1), medium (scores 2-6) and high (scores 7-18) physical activity using a validated and purpose-designed physical activity questionnaire ${ }^{(18)}$.

\section{Statistical analysis}

The Shapiro-Wilk test and quantile-quantile plots were used for normality testing. Normally distributed data are reported as mean values and standard deviations and non-normal data as medians and interquartile ranges (IQR). Baseline characteristics, micronutrient intake and percentage of participants below the Lower Reference Nutrient Intake (LRNI), EAR, RNI and upper level (UL) were calculated using descriptive statistics. If available, LRNI was the preferred DRV to be reported. The LRNI is only supposed to meet the needs of $2.5 \%$ of a given population and intakes below this are likely to be 'inadequate'. When appropriate, sex differences were assessed with the two-sample $t$ test or the $\chi^{2}$ test for normally distributed continuous variables and categorical variables, respectively. Most micronutrient intake data were continuous and non-normally distributed; therefore, sex differences 
were determined by the Mann-Whitney $U$ test. Vitamin and mineral intakes were stratified by housing, living arrangements (with whom participants lived), years of full-time education, social class (coded to the NS-SEC three-class system $^{(17)}$ ) and physical activity groups and compared by multinomial logistic regression. Apart from energy, which was adjusted for sex only, all vitamins and minerals were adjusted for sex and energy. Exploratory and statistical analyses were conducted using the IBM statistical tool SPSS version 22.0. Values of $P<0.05$ were considered significant.

\section{Results}

\section{Vitamin intakes}

Men had higher vitamin intakes than women except for vitamin $\mathrm{C}$ (Table 2). However, the overall higher vitamin intake by men disappeared when the results were expressed per $1 \mathrm{MJ}$. Specifically, women's vitamin A intake was $12 \mu \mathrm{g}$ retinol equivalents $(\mathrm{RE}) / \mathrm{MJ}$ or $13 \%$ higher $(P=0.008)$ and vitamin $\mathrm{C}$ intake was $20 \mathrm{mg} / \mathrm{MJ}$ or $28 \%$ higher $(P=0 \cdot 001)$ compared with men. Despite $43 \%$ of the participants ( $n 335$ ) consuming one or more supplements on a regular basis (Table 1), on a population level, vitamin intakes changed only marginally when supplements were included, except for vitamin A and D, which increased by $19.2 \%$ (from 620 to $752 \mu \mathrm{g}-\mathrm{RE}$ ) and by $22.5 \%$ (from 2.0 to $2 \cdot 5 \mu \mathrm{g}$ ), respectively (online Supplementary Table S1). Owing to the modest differences to micronutrient intakes when including supplements, and limitations in supplement frequency data, micronutrient consumption from supplements was not included in the main analysis.

\section{Vitamin food sources}

Fig. 1 shows the percentage contribution of food groups to vitamin intake for all participants. Meat and meat products contributed to $40 \%$ of vitamin A intake - the majority coming from liver and liver products and dishes (94.4\%). Vegetables were the second highest contributors (22.4\%) to vitamin A intake, of which most came from carrots $(71 \cdot 1 \%)$. CCP were the

Table 1. Health and socio-demographic characteristics of the Newcastle $85+$ Study participants with complete dietary data by sex (Numbers and percentages)

\begin{tabular}{|c|c|c|c|c|c|c|c|}
\hline & \multicolumn{2}{|c|}{ All } & \multicolumn{2}{|c|}{ Men } & \multicolumn{2}{|c|}{ Women } & \multirow[b]{2}{*}{$P^{\star}$} \\
\hline & $\%$ & $n$ & $\%$ & $n$ & $\%$ & $n$ & \\
\hline Sex & & 793 & 38 & 302 & 62 & 491 & - \\
\hline Housing & & & & & & & 0.001 \\
\hline Standard & 78 & 620 & 85 & 256 & 74 & 364 & \\
\hline Sheltered & 17 & 137 & 12 & 37 & 21 & 100 & \\
\hline Institutional & 4 & 34 & 3 & 8 & 5 & 26 & \\
\hline Living arrangements $†$ & & & & & & & $<0.001$ \\
\hline Alone & 61 & 437 & 42 & 119 & 74 & 318 & \\
\hline Spouse only & 28 & 204 & 51 & 145 & 14 & 59 & \\
\hline Others & 11 & 79 & 8 & 23 & 13 & 56 & \\
\hline Education & & & & & & & 0.608 \\
\hline$\leq 9$ years & 64 & 501 & 61 & 184 & 66 & 317 & \\
\hline 10-11 years & 23 & 183 & 25 & 75 & 23 & 108 & \\
\hline $12-20$ years & 12 & 97 & 13 & 39 & 12 & 58 & \\
\hline Past occupation (NS-SEC) & & & & & & & $<0.001$ \\
\hline Higher managerial/administrative/professional (class 1) & 34 & 259 & 40 & 118 & 31 & 141 & \\
\hline Intermediate (class 2 ) & 15 & 109 & 8 & 23 & 19 & 86 & \\
\hline Routine and manual (class 3 ) & 51 & 385 & 52 & 155 & 50 & 230 & \\
\hline Physical activity & & & & & & & $<0.001$ \\
\hline Low & 22 & 176 & 20 & 60 & 24 & 116 & \\
\hline Medium & 44 & 343 & 33 & 99 & 50 & 244 & \\
\hline High & 34 & 270 & 47 & 142 & 26 & 128 & \\
\hline Energy (MJ) & 6.65 & $5 \cdot 49-8 \cdot 16$ & $7 \cdot 73$ & $6 \cdot 36-9 \cdot 20$ & $6 \cdot 15$ & $5 \cdot 09-7 \cdot 25$ & $<0.001 \ddagger$ \\
\hline Carbohydrate (\% en) & $46 \cdot 8$ & $42 \cdot 6-51 \cdot 5$ & $46 \cdot 8$ & $42 \cdot 7-52 \cdot 0$ & $46 \cdot 8$ & $42 \cdot 5-51.4$ & $0.760 \S$ \\
\hline Fat (\% en) & $36 \cdot 8$ & $32 \cdot 0-41 \cdot 8$ & $36 \cdot 4$ & $31 \cdot 6-41 \cdot 1$ & $37 \cdot 2$ & $32 \cdot 2-42 \cdot 2$ & $0.093 \S$ \\
\hline Protein (\% en) & $15 \cdot 7$ & $13 \cdot 5-18 \cdot 3$ & $15 \cdot 9$ & $13 \cdot 8-18 \cdot 9$ & $15 \cdot 5$ & $13 \cdot 6-17 \cdot 9$ & $0.006 \S$ \\
\hline Dietary supplement use & & & & & & & 0.252 \\
\hline None & 58 & 456 & 62 & 185 & 55 & 271 & \\
\hline 1 & 29 & 227 & 27 & 81 & 30 & 146 & \\
\hline $2+$ & 14 & 108 & 12 & 35 & 15 & 73 & \\
\hline Dietary supplement type & & & & & & & 0.590 \\
\hline Fish and $n-3$ oil & 48 & 162 & 48 & 56 & 48 & 106 & \\
\hline Mineral/vitamin preparations & 10 & 32 & 8 & 9 & 11 & 23 & \\
\hline Multivitamin and/or multimineral & 12 & 39 & 10 & 12 & 12 & 27 & \\
\hline Other & 31 & 102 & 34 & 39 & 29 & 63 & \\
\hline
\end{tabular}

NS-SEC, National Statistics Socio-economic Classification; \% en, percentage of energy.

${ }^{*} \chi^{2}$ Test for no sex difference unless otherwise stated.

† Excludes participants living in institutions.

$\ddagger$ Mann-Whitney $U$ test for no sex difference.

$\S$ Independent $t$ test for no sex difference. 
(a)

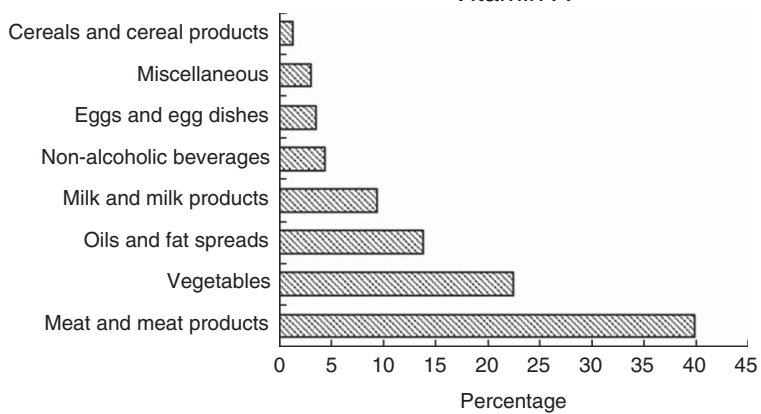

(c)

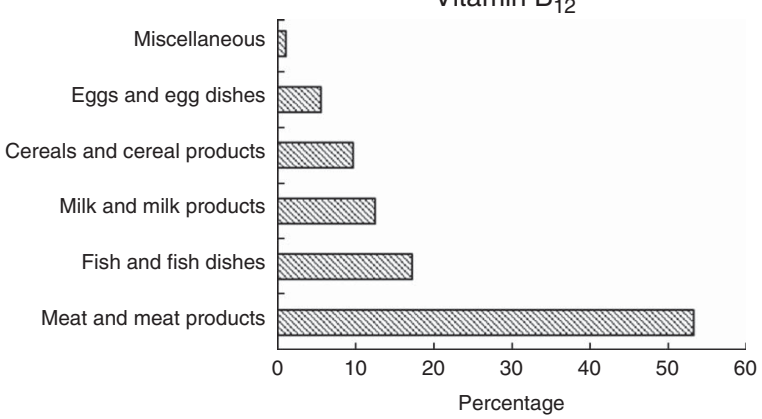

(e)

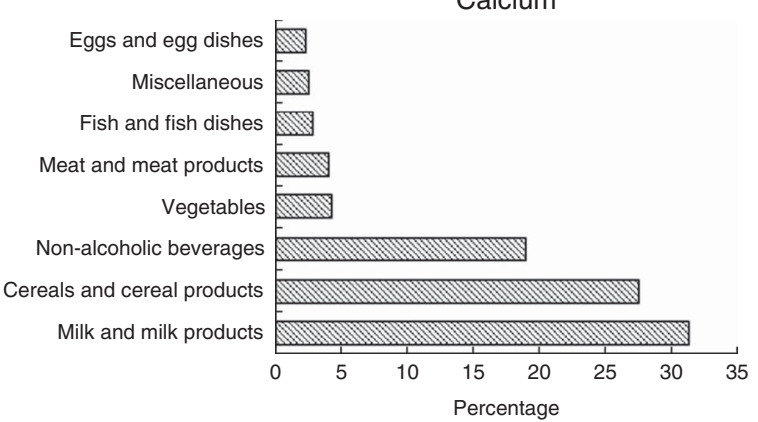

(g)

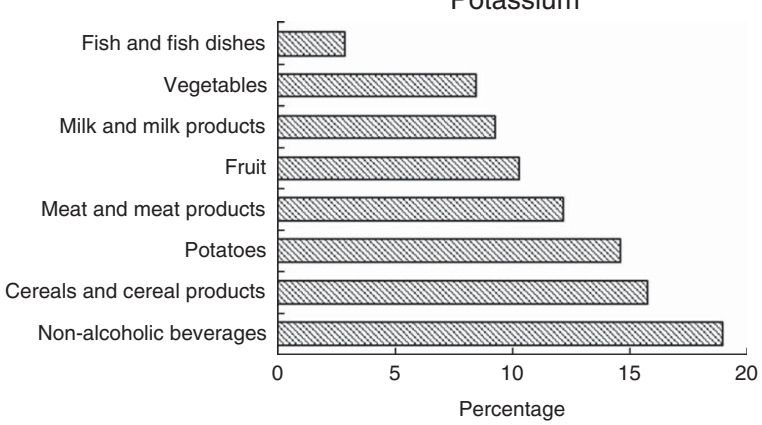

(b)

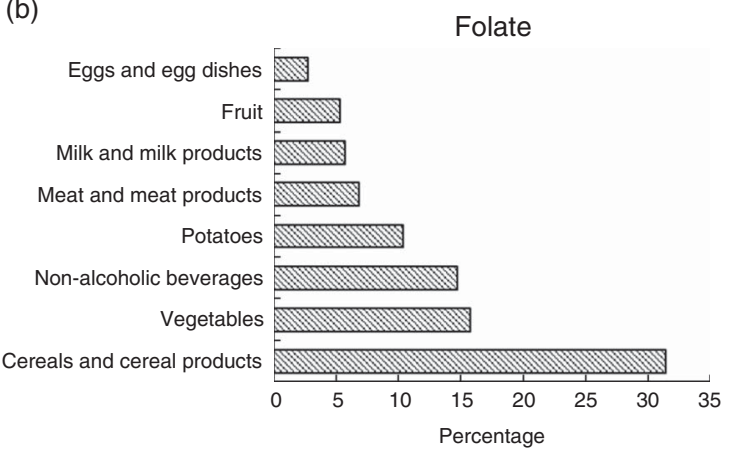

(d)

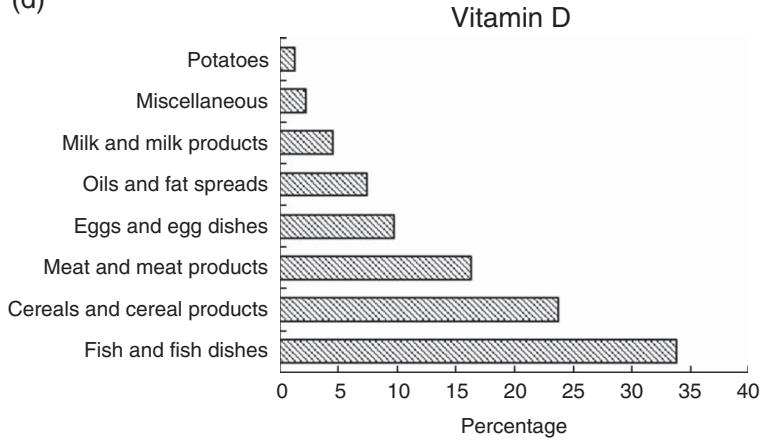

(f)

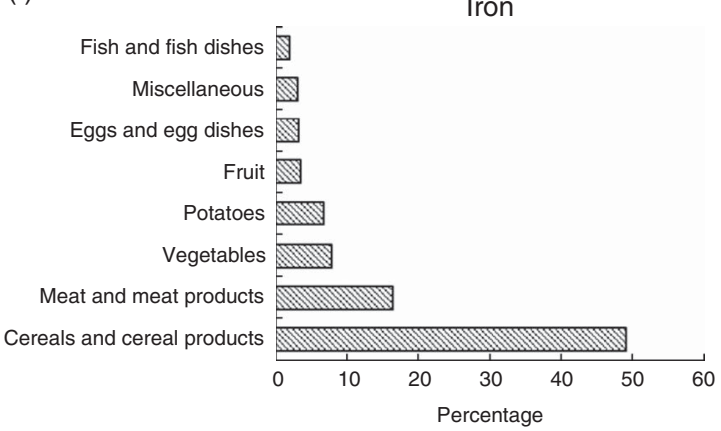

(h)

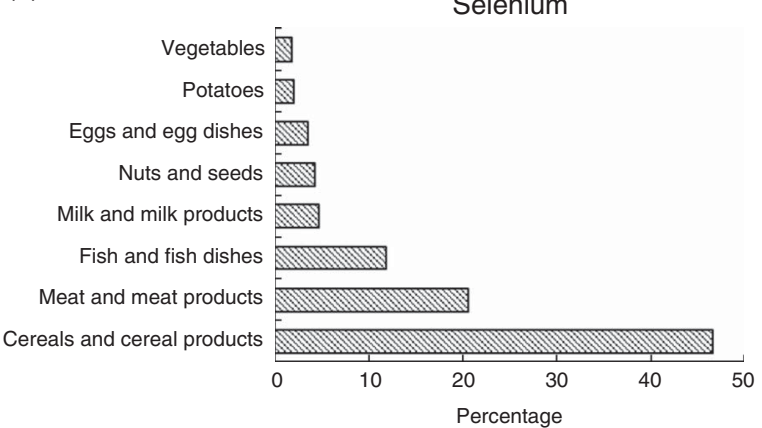

Fig. 1. Contribution (\%) of fifteen food groups to average (a) vitamin $A$, (b) folate, (c) vitamin $B_{12}$, (d) vitamin $D$, (e) calcium, (f) iron, (g) potassium and (h) selenium intakes in the Newcastle 85+ Study.

highest contributors $(31.5 \%)$ to folate intake, $86.9 \%$ of which came from bread and breakfast cereals. Vegetables were the second highest contributors (15.8\%) to folate intake with $42.4 \%$ coming from cruciferous vegetables. Half (49.6\%) of the vitamin $\mathrm{B}_{12}$ intake from meat and meat products $(52.3 \%)$ came from liver and liver products and dishes; one-third (33.8\%) of vitamin D intake came from fish and fish dishes $(98.9 \%$ of which was from oily fish) and $23.8 \%$ from CCP ( $45.2 \%$ of which was from breakfast cereals and $43.3 \%$ from buns, cakes, pastries and fruit pies). 


\section{Mineral intakes}

Similar to vitamin intake, men had an overall higher mineral intake than women ( $24 \%$ higher on average) (Table 2$)$. When expressed per $1 \mathrm{MJ}$ of energy, men still had higher intakes of Fe $(P=0.005)$, Se $(P=0.028)$ and $\mathrm{Zn}(P<0.001)$ compared with women but lower $\mathrm{Ca}$ intakes $(P=0 \cdot 008)$. On a population level, supplement contribution to mineral intakes was almost negligible (online Supplementary Table S1). The highest difference between dietary intake with and without supplements was only $2.7 \%$ for $\mathrm{Zn}$ (from $7 \cdot 1$ to $7 \cdot 3 \mathrm{mg}$ ).

\section{Mineral food sources}

Fig. 1 shows the percentage contribution of food groups to vitamin intakes for all participants. Milk and milk products were the highest contributors (31.3\%) to Ca intake while CCP was second with $27.5 \%$ (36.6\% of which came from bread). Nonalcoholic beverages contributed $18.9 \%$ to $\mathrm{Ca}$ intake mainly because tea and coffee (with added milk) were included in this group (95.4\% came from tea, coffee and water). Non-alcoholic beverages accounted for $19 \%$ of $\mathrm{K}$ intake $(81.5 \%$ of which was from tea, coffee and water). CCP (15.8\%) and potatoes (14.6\%) were the second and third, respectively, highest contributors to $\mathrm{K}$ intake. CCP explained $46.7 \%$ of Se intake and $93.2 \%$ of this came from bread. Meat and meat products made a higher contribution to intakes of $\mathrm{Fe}(19 \cdot 3 v .14 \cdot 2 \%)$, vitamin $\mathrm{D}(20 \cdot 3 v$. $13.4 \%)$ and vitamin $\mathrm{B}_{12}(59 \cdot 2$ v. $47.8 \%)$ for men than for women (data not shown).

\section{Micronutrient adequacy}

The failure of both men and women in the Newcastle 85+ Study to meet several micronutrients' DRV was widespread (Fig. 2 and online Supplementary Table S2). In all, $20 \%$ of the participants had intakes below the LRNI for $\mathrm{Mg}, \mathrm{K}$ and Se. The proportion of participants below the LRNI for vitamin A, vitamin $\mathrm{B}_{12}$ and $\mathrm{Zn}$ was around $10 \%$. However, $4.6 \%$ ( $n$ 36) of the participants had vitamin A intakes above the UL. The widest disparity between intake and recommendations was seen for vitamin D intake, with $>95 \%$ ( $n$ 756) of participants having intakes below the RNI for vitamin D of $10 \mu \mathrm{g} / \mathrm{d}$ (EAR or LRNI for vitamin D have not been defined for the $\mathrm{UK})^{(6)}$, and $52.7 \%(n$ 418) of the participants were below the LRNI for Se. In contrast, $82 \cdot 2 \%(n 652)$ of the participants were above the RNI for $\mathrm{Na}$ of $1600 \mathrm{mg} / \mathrm{d}^{(6)}$. The 95th percentile of $\mathrm{Na}$ intake was $4663 \mathrm{mg} / \mathrm{d}$, and among those with intakes above the RNI the median intake was $2594 \mathrm{mg}$. Fewer men had intakes below the DRV for vitamin $\mathrm{B}_{12}, \mathrm{Fe}$, $\mathrm{K}$ and folate than women. The widest difference between men and women not meeting the LRNI was for vitamin $\mathrm{B}_{12}$ (5.0 v. $12.4 \%, P<0.001)$ and $\mathrm{Fe}(2.3 v .7 .8 \%, P<0.001)$. Meat and meat products were top contributors for both micronutrients.

\section{Micronutrient intake by housing, socio-economic status and physical activity}

Table 3 reports the energy, vitamin and mineral intakes in the Newcastle $85+$ Study stratified by housing, living arrangements, years of full-time education, social class (past occupation according to NS-SEC) and physical activity. All micronutrient models were adjusted for sex and food energy intake.

Energy and vitamin D intakes were higher in participants who lived in institutional care (nursing or residential) than in standard housing. Conversely, vitamin $\mathrm{E}, \mathrm{Mg}$ and $\mathrm{K}$ intakes were lower in institutional than in standard housing. Participants who lived with their spouses had higher $\mathrm{K}$ and Se intakes than those who lived alone. Those with 12 or more years of fulltime education had higher intakes of vitamin C, vitamin D, Ca, $\mathrm{Mg}$ and $\mathrm{K}$ than those with $\leq 9$ years of full-time education. Social class also predicted the intakes of several vitamins and minerals. Participants with previous higher managerial, administrative and professional occupations (class 1) had higher intakes of vitamin $\mathrm{B}_{2}$, folate, $\mathrm{Ca}, \mathrm{Fe}, \mathrm{Mg}, \mathrm{K}$ and $\mathrm{Zn}$ than those who had routine and manual occupations (class 3 ). Those with high physical activity had a more nutrient-dense diet including vitamin $\mathrm{B}_{6}$, folate, vitamin $\mathrm{E}$, vitamin $\mathrm{C}, \mathrm{Fe}, \mathrm{Mg}, \mathrm{K}$ and $\mathrm{Zn}$ than those with lower physical activity.

\section{Discussion}

The median vitamin D, Mg, $\mathrm{K}$ and Se intakes were 2.0 (IQR 1.26.5) $\mu \mathrm{g} / \mathrm{d}, 215$ (IQR 166-266) mg/d, 2477 (IQR 1890-3023) mg/d and $39 \cdot 0($ IQR $27 \cdot 3-55 \cdot 5) \mu \mathrm{g} / \mathrm{d}$, respectively. Participants with more full-time years in education, from higher social class and those who were more physically active had more nutrientdense diets including several vitamins and minerals. The most notable findings are that $20 \%$ or more of the participants in the Newcastle $85+$ Study had intakes below the LRNI for Mg, K and Se and that $>95 \%$ of the participants were below the RNI of $10 \mu \mathrm{g} / \mathrm{d}$ of vitamin D. Very old adults may be at increased risk of micronutrient deficiencies, which contributes to disability, frailty and loss of physical function ${ }^{(5)}$. Therefore, a deeper understanding of the dietary habits of the very old is an important prerequisite for developing evidence-based, age-specific dietary recommendations.

\section{Comparison with other studies}

Since the 1994/1995 NDNS of people aged 65 years and over, which included 172 men and 287 women aged 85 years and over (all non-institutionalised), no study has described micronutrient intakes and food sources in a large sample of very old adults in the UK. Most vitamin and mineral intakes were similar between the two studies, except for $\beta$-carotene (1141 $v$. $1516 \mu \mathrm{g} / \mathrm{d})$, vitamin $\mathrm{C}(41.4 v .56 .5 \mathrm{mg} / \mathrm{d})$ and Ca (644 v. $731 \mathrm{mg} / \mathrm{d}$ ), which were higher in the Newcastle 85+ Study participants (intakes from food sources only) ${ }^{(19)}$. In the 1994/ 1995 NDNS, less vitamin A (34v. 40\%) and vitamin $\mathrm{B}_{12}$ (43v. $53 \%$ ) were derived from meat and meat products and less $\mathrm{K}$ from non-alcoholic drinks (10 v. 19\%). However, more vitamin $\mathrm{B}_{12}$ (29v. 13\%), Ca (54v. 31\%) and $\mathrm{K}$ (20v. 9\%) came from milk and milk products in the 1994/1995 NDNS than in the Newcastle $85+$ Study. The food sources of vitamin D were considerably different between the studies with fish and fish dishes making a lower contribution to intake (17v. 34\%), whereas fat spreads made a higher contribution (23v. 8\%) in 
Table 2. Daily energy, vitamin and mineral intakes of the Newcastle $85+$ Study participants by sex and per $1 \mathrm{MJ}$ of energy*

(Medians and interquartile ranges (IQR))

\begin{tabular}{|c|c|c|c|c|c|c|c|c|c|}
\hline \multirow[b]{2}{*}{ Micronutrients } & \multicolumn{2}{|c|}{ All } & \multicolumn{3}{|c|}{ Men } & \multicolumn{3}{|c|}{ Women } & \multirow[b]{2}{*}{$P \dagger$} \\
\hline & Median & IQR & Median & IQR & Median/1 MJ & Median & IQR & Median/1 MJ & \\
\hline Energy $(\mathrm{MJ}) \ddagger$ & 6.65 & $5 \cdot 49-8 \cdot 16$ & 7.73 & $6 \cdot 36-9 \cdot 20$ & - & $6 \cdot 15$ & $5 \cdot 09-7.25$ & - & $<0.001$ \\
\hline \multicolumn{10}{|l|}{ Vitamins } \\
\hline Vitamin A ( $\mu \mathrm{g} R E$ ) & 620 & $398-910$ & 674 & $414-988$ & 86.5 & 593 & $390-851$ & 98.5 & 0.008 \\
\hline$\beta$-Carotene $(\mu \mathrm{g})$ & 1516 & $517-2883$ & 1769 & $606-3167$ & 212.5 & 1335 & $488-2666$ & $215 \cdot 0$ & 0.577 \\
\hline Vitamin $B_{2}(\mathrm{mg})$ & 1.5 & $1.2-1.9$ & 1.7 & $1 \cdot 3-2 \cdot 1$ & 0.22 & 1.4 & $1 \cdot 1-1 \cdot 8$ & 0.23 & 0.138 \\
\hline Vitamin $B_{6}(\mathrm{mg})$ & 1.7 & $1 \cdot 2-2 \cdot 1$ & $2 \cdot 0$ & $1.5-2.5$ & 0.25 & 1.5 & $1.1-1.9$ & 0.25 & 0.217 \\
\hline Folate $(\mu \mathrm{g})$ & 208 & $157-264$ & 245 & $183-295$ & 30.9 & 189 & $146-243$ & 31.7 & 0.564 \\
\hline Vitamin $B_{12}(\mu \mathrm{g})$ & 2.9 & $1 \cdot 9-4.4$ & 3.4 & $2 \cdot 2-5 \cdot 2$ & 0.46 & 2.6 & $1.6-3.9$ & 0.42 & 0.047 \\
\hline Vitamin $\mathrm{E}(\mathrm{mg})$ & 4.7 & $3.2-7.5$ & 5.0 & $2 \cdot 4-8 \cdot 3$ & 0.65 & 4.5 & $2.9-6.9$ & 0.69 & 0.128 \\
\hline Vitamin C (mg) & 56.5 & $30 \cdot 5-99 \cdot 1$ & 55.5 & $32 \cdot 4-98 \cdot 4$ & $7 \cdot 10$ & $57 \cdot 2$ & $30.0-99.4$ & $9 \cdot 27$ & 0.001 \\
\hline Vitamin D $(\mu \mathrm{g})$ & 2.0 & $1 \cdot 2-6.5$ & $2 \cdot 3$ & $1.4-3.7$ & 0.33 & 1.8 & $1.0-2 \cdot 9$ & 0.30 & 0.200 \\
\hline \multicolumn{10}{|l|}{ Minerals } \\
\hline $\mathrm{Ca}(\mathrm{mg})$ & 731 & $554-916$ & 829 & $634-1007$ & 103.7 & 683 & $537-862$ & 111.2 & 0.008 \\
\hline $\mathrm{Fe}(\mathrm{mg})$ & 8.7 & $6 \cdot 7-11 \cdot 6$ & 10.5 & $8 \cdot 4-13.5$ & 1.35 & 7.8 & $6.1-9.9$ & 1.28 & 0.005 \\
\hline $\mathrm{Mg}(\mathrm{mg})$ & 215 & $166-266$ & 251 & $196-309$ & 32.6 & 196 & $156-239$ & 32.4 & 0.316 \\
\hline $\mathrm{K}(\mathrm{mg})$ & 2477 & $1890-3023$ & 2798 & $2230-3448$ & 356.6 & 2262 & $1804-2797$ & 373.4 & $0 \cdot 100$ \\
\hline $\mathrm{Na}(\mathrm{mg}) \S$ & 2388 & $1829-3188$ & 2987 & $2216-3743$ & 372.1 & 2162 & $1691-2707$ & 361.6 & 0.101 \\
\hline $\mathrm{Se}(\mu \mathrm{g})$ & 39.0 & $27 \cdot 3-55 \cdot 5$ & $48 \cdot 3$ & $33.9-65.1$ & 6.19 & 35.2 & $25 \cdot 3-48 \cdot 4$ & 5.83 & 0.028 \\
\hline $\mathrm{Zn}(\mathrm{mg})$ & $7 \cdot 1$ & $5 \cdot 5-9 \cdot 6$ & 8.6 & $6 \cdot 8-11 \cdot 1$ & $1 \cdot 12$ & $6 \cdot 3$ & $5 \cdot 1-8 \cdot 2$ & 1.05 & $<0.001$ \\
\hline
\end{tabular}

$\mathrm{RE}$, retinol equivalents.

* Does not include supplements.

† Mann-Whitney Utest for no sex difference (median/1 MJ of energy).

$\S$ Does not include table salt and salt used for cooking. 
(a)

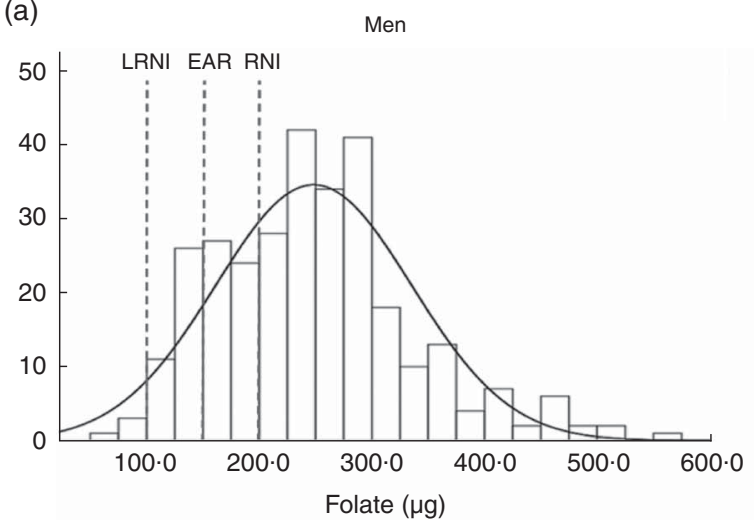

(c)

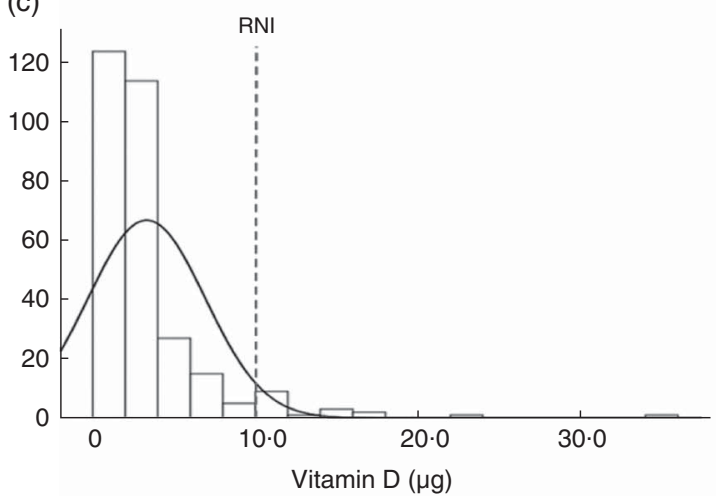

(e)

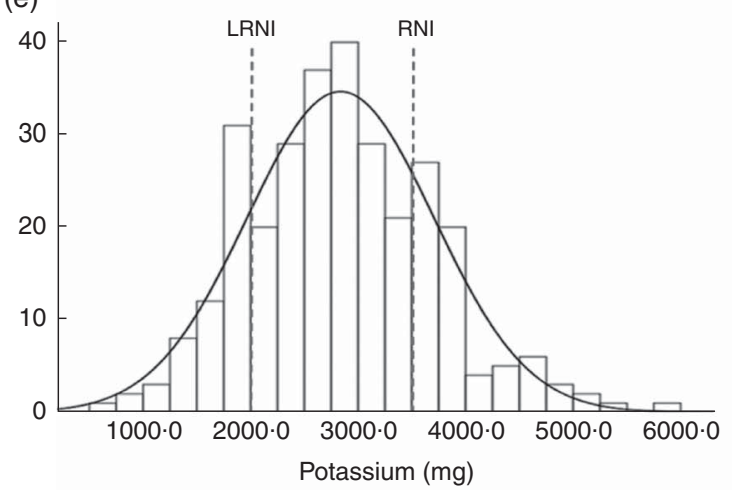

(g)

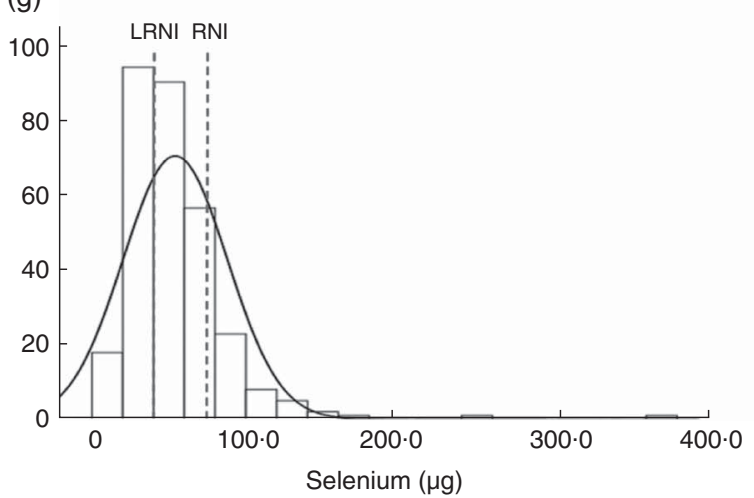

(b)

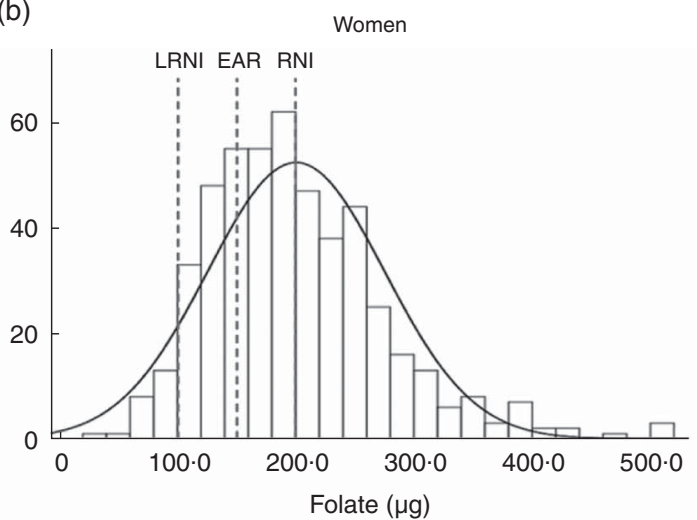

(d)

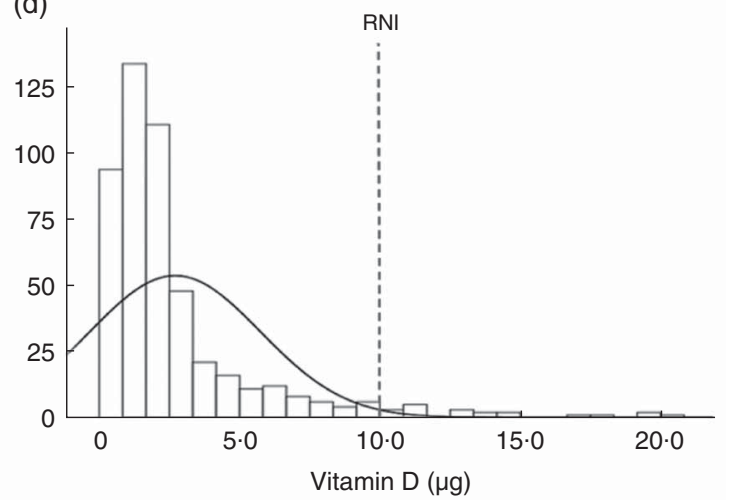

(f)

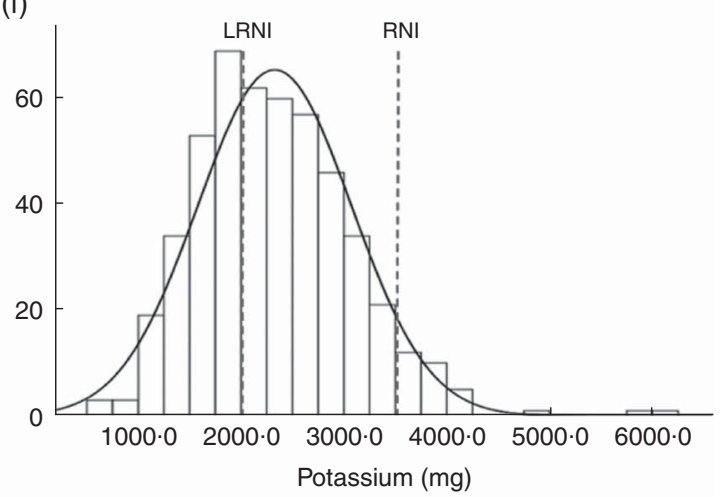

(h)

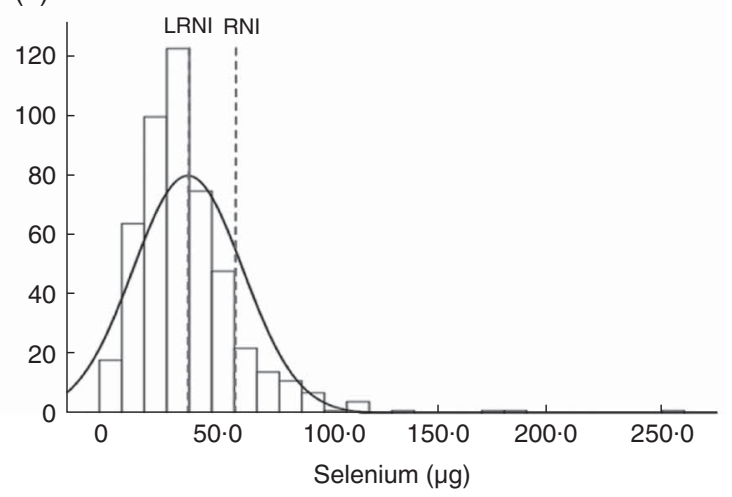

Fig. 2. Intake distribution and inadequacy of folate $(\mu \mathrm{g})$ in (a) men and (b) women, of vitamin $D(\mu \mathrm{g})$ in (c) men and (d) women, of potassium ( $\mu \mathrm{g})$ in (e) men and (f) women and of selenium $(\mu \mathrm{g})$ in $(\mathrm{g})$ men and $(\mathrm{h})$ women. -......, the LRNI, EAR and RNI for people aged 50 years and over, except for vitamin D, which is set for $\geq 65$ years $^{(6)}$. RNI, Reference Nutrient Intake; EAR, estimated average intake; LRNI, Lower Reference Nutrient Intake. 
Table 3. Daily energy, vitamin and mineral intakes according to demographic, socio-economic and lifestyle characteristics †‡

\begin{tabular}{|c|c|c|c|c|c|c|c|c|c|c|c|c|c|c|c|}
\hline \multirow[b]{2}{*}{ Micronutrients } & \multicolumn{3}{|c|}{ Housing } & \multicolumn{3}{|c|}{ Live with } & \multicolumn{3}{|c|}{ Education (years) } & \multicolumn{3}{|c|}{ Past occupation (NS-SEC) } & \multicolumn{3}{|c|}{ Physical activity } \\
\hline & $\begin{array}{l}\text { Stand } \\
(n \text { 620) }\end{array}$ & $\begin{array}{c}\text { Sheltered } \\
(n \text { 137) }\end{array}$ & $\begin{array}{l}\text { Institut } \\
(n 34)\end{array}$ & $\begin{array}{l}\text { Alone } \\
\text { (n 437) }\end{array}$ & $\begin{array}{l}\text { Spouse } \\
(n \text { 204) }\end{array}$ & $\begin{array}{l}\text { Others } \\
(n 79)\end{array}$ & $\begin{array}{c}\leq 9 \\
(n 501)\end{array}$ & $\begin{array}{c}10-11 \\
(n 183)\end{array}$ & $\begin{array}{l}\geq 12 \\
(n \text { 97) }\end{array}$ & $\begin{array}{l}\text { Class } 1 \\
(n 385)\end{array}$ & $\begin{array}{l}\text { Class } 2 \\
(n 109)\end{array}$ & $\begin{array}{l}\text { Class } 3 \\
(n 259)\end{array}$ & $\begin{array}{c}\text { Low } \\
(n 176)\end{array}$ & $\begin{array}{l}\text { Medium } \\
\text { (n 343) }\end{array}$ & $\begin{array}{l}\text { High } \\
(n 270)\end{array}$ \\
\hline \multicolumn{16}{|l|}{ Vitamins } \\
\hline $\begin{array}{r}\text { Vitamin A } \\
(\mu \mathrm{g} R E)\end{array}$ & 606 & 623 & 709 & 600 & 642 & 582 & 602 & 625 & 667 & 639 & $636^{*}$ & 600 & 627 & 599 & 648 \\
\hline$\beta$-Carotene $(\mu \mathrm{g})$ & 1589 & 1093 & 1546 & 1381 & 1792 & 1365 & 1492 & 1493 & 1470 & 1575 & 1576 & 1339 & 1382 & 1339 & 1730 \\
\hline Vitamin $B_{2}(\mathrm{mg})$ & 1.5 & 1.5 & 1.8 & 1.4 & 1.6 & 1.4 & 1.5 & 1.6 & $1 \cdot 7$ & $1.6^{\star \star}$ & $1.5^{\star}$ & 1.5 & 1.6 & 1.4 & 1.6 \\
\hline Vitamin $B_{6}(\mathrm{mg})$ & 1.7 & 1.6 & 1.7 & 1.6 & 1.9 & 1.6 & 1.6 & 1.7 & 1.8 & 1.7 & $1 \cdot 7$ & 1.6 & 1.5 & $1 \cdot 6^{\star}$ & $1.9^{\star \star \star}$ \\
\hline Folate $(\mu \mathrm{g})$ & 208 & 195 & 231 & 195 & 231 & 191 & 201 & 209 & 234 & $214^{\star}$ & 208 & 203 & 185 & 201 & $232^{\star \star}$ \\
\hline Vitamin $B_{12}(\mu \mathrm{g})$ & $2 \cdot 9$ & $2 \cdot 7$ & 3.8 & $2 \cdot 7$ & $3 \cdot 1$ & $2 \cdot 2$ & $2 \cdot 8$ & $3 \cdot 1$ & 3.0 & $3 \cdot 0$ & $2 \cdot 8^{\star}$ & $2 \cdot 8$ & 3.0 & 2.5 & $3 \cdot 2$ \\
\hline Vitamin E (mg) & 4.7 & 4.7 & $3 \cdot 9^{*}$ & 4.7 & $4 \cdot 8$ & 4.6 & 4.7 & 4.7 & $5 \cdot 1$ & 4.7 & $5 \cdot 2$ & 4.5 & 4.5 & 4.4 & $5 \cdot 2^{*}$ \\
\hline Vitamin C (mg) & 59.0 & $49 \cdot 6$ & $62 \cdot 1$ & $55 \cdot 2$ & $56 \cdot 7$ & $62 \cdot 3$ & 54.8 & 55.5 & $80 \cdot 0^{\star *}$ & $61 \cdot 7$ & 64.5 & $52 \cdot 1$ & $46 \cdot 6$ & $56 \cdot 4$ & $66 \cdot 6^{\star}$ \\
\hline Vitamin D $(\mu \mathrm{g})$ & 1.9 & 1.9 & $3 \cdot 5^{\star *}$ & 1.8 & $2 \cdot 1$ & 1.9 & 1.9 & $2 \cdot 1^{*}$ & $2 \cdot 1^{*}$ & $2 \cdot 0$ & 1.9 & 1.9 & $2 \cdot 6$ & $1.8^{\star}$ & $2 \cdot 1$ \\
\hline \multicolumn{16}{|l|}{ Minerals } \\
\hline $\mathrm{Ca}(\mathrm{mg})$ & 730 & 731 & 736 & 713 & 799 & $638^{*}$ & 710 & 738 & $778^{*}$ & $753^{*}$ & 730 & 722 & 735 & 702 & 771 \\
\hline $\mathrm{Fe}(\mathrm{mg})$ & 8.9 & $8 \cdot 0^{\star \star \star}$ & 9.0 & $8 \cdot 3$ & 9.8 & 7.9 & $8 \cdot 3$ & 9.6 & 9.9 & $9 \cdot 3^{* *}$ & 8.7 & 8.6 & $8 \cdot 6$ & $8 \cdot 4^{*}$ & $9.5^{\star \star}$ \\
\hline $\mathrm{Mg}(\mathrm{mg})$ & 220 & $205^{\star \star}$ & $195^{\star \star \star}$ & 209 & 236 & 196 & 211 & 216 & $235^{\star \star}$ & $226^{\star \star \star}$ & $223^{\star \star \star}$ & 209 & 197 & $208^{\star \star \star}$ & $235^{\star \star \star}$ \\
\hline $\mathrm{K}(\mathrm{mg})$ & 2504 & $2445^{\star}$ & $2363^{\star \star}$ & 2348 & $2738^{\star}$ & 2276 & 2397 & 2495 & $2904^{\star \star}$ & $2656^{\star \star \star}$ & 2440 & 2402 & 2278 & $2381^{\star \star}$ & $2725^{\star \star \star}$ \\
\hline $\mathrm{Na}(\mathrm{mg}) \|$ & 2357 & $2482^{*}$ & 2678 & 2363 & 2532 & $2077^{\star}$ & 2351 & 2464 & 2390 & 2381 & 2363 & 2392 & 2401 & $2285^{\star}$ & 2573 \\
\hline $\mathrm{Se}(\mu \mathrm{g})$ & $39 \cdot 1$ & $36 \cdot 2$ & 41.5 & 37.9 & $40 \cdot 8^{\star}$ & 34.0 & 38.1 & $40 \cdot 0$ & 39.0 & $38 \cdot 1$ & $39 \cdot 7^{\star}$ & $39 \cdot 3$ & $37 \cdot 8$ & $38 \cdot 1$ & $41 \cdot 1$ \\
\hline Zn (mg) & $7 \cdot 2$ & $7 \cdot 0$ & 7.4 & $6 \cdot 9$ & 7.9 & $6 \cdot 2$ & $7 \cdot 0$ & 7.3 & $7 \cdot 6$ & $7 \cdot 4^{\star \star}$ & $7 \cdot 2^{*}$ & 7.0 & $7 \cdot 0$ & $6 \cdot 7$ & $8 \cdot 0^{*}$ \\
\hline
\end{tabular}

NS-SEC, National Statistics Socio-economic Classification; Stand, standard; Institut, institutional housing; Class 1, higher managerial, administrative and professional occupations; Class 2, intermediate occupations; Class 3, routine or manual occupations.
${ }^{*} P<0.05,{ }^{\star *} P<0.01,{ }^{* * *} P<0.001$. † All models were adjusted for sex and energy intake except for energy intake, which was only adjusted for sex. Standard housing, living alone, $\leq 9$ years of full-time education, class 3 of past occupation and low physical activity were the

‡ Does not include supplements.

$\S$ Does not include energy from alcohol.

॥ Does not include table salt and salt used for cooking. 
the $1994 / 1995$ NDNS than in our study ${ }^{(19)}$. The observed differences are unlikely to be due to fortification policies. The Newcastle 85+ Study included 85-year-olds only, whereas the 1994/1995 NDNS included those aged 85 years and over. Other possible reasons include different dietary assessments (4-d weighted diet record $v, 2 \times 24 \mathrm{~h}-\mathrm{MPR}$ ) that diverged by more than a decade.

The European Prospective Investigation into Cancer and Nutrition (EPIC)-Oxford third follow-up questionnaire in 2010-2014 included 411 men and 872 women aged 80 years and over ${ }^{(20)}$. Intakes of all vitamins and minerals were at least $20 \%$ higher in the EPIC-Oxford than in the Newcastle 85+ Study participants (Tim Key \& Paul Appleby, personal communication). Different descriptive statistics and dietary assessment methods used, different ages ( $\geq 80 v$. 85-year-olds) and characteristics of the participants ( $14 \%$ of EPIC-Oxford participants were vegetarians) are potential explanations for the wide differences observed in micronutrient intakes.

The current NDNS rolling programme (from 2008/2009 to $2011 / 2012$ or years 1 to 4 ) does not yet have enough very old adults for comparison with our study. Nonetheless, it included 428 adults (191 men and 237 women) aged $\geq 65$ years $^{(21)}$. Although energy intakes were similar between both the studies, vitamin and mineral intakes (without supplements) were slightly higher in the NDNS than in the Newcastle 85+ Study (except for $\mathrm{Na}$ where intakes were 1947 and $2383 \mathrm{mg} / \mathrm{d}$, respectively). More than $10 \%$ of the participants had intakes of $\mathrm{Mg}, \mathrm{K}$ and Se below the $\mathrm{LRNI}^{(21)}$. Similarly, $>20 \%$ of the Newcastle $85+$ Study participants were also below the LRNI for these minerals.

\section{Public health implications}

In the Newcastle $85+$ Study, men had higher energy intakes than women; therefore, it was not unexpected that intakes of most micronutrients by men were also higher. However, when vitamin and mineral intakes were expressed per $1 \mathrm{MJ}$, vitamin $\mathrm{A}, \mathrm{C}$ and $\mathrm{Ca}$ intakes were higher in women than in men. Conversely, men's diets were more nutrient dense in vitamin $\mathrm{B}_{12}$, Fe and Se compared with women. Higher meat and meat products consumption by men was the main cause for these differences.

Several micronutrient intakes were lower than the current DRV. In all, $>20 \%$ of the participants were below the LRNI for $\mathrm{Mg}, \mathrm{K}$ and Se, whereas $95.3 \%$ of the participants were below the RNI for vitamin D (the Scientific Advisory Committee tentatively set the same RNI as the Committee on Medical Aspects of Food and Nutrition Policy $\left.{ }^{(22)}\right)$. This is of concern because $\mathrm{Mg}$ is associated with physical performance ${ }^{(23)}$, systemic inflammation, endothelial function ${ }^{(24)}$ and bone mineral density in older adults ${ }^{(25)}$; inadequate Se has been linked with anaemia ${ }^{(26)}$, cancer and all-cause mortality ${ }^{(27)}$; and low vitamin D intake has been consistently associated with musculoskeletal $^{(4)}$ and extra-skeletal outcomes, including cognitive impairment and mortality ${ }^{(28,29)}$. However, the major 'inadequacy' in vitamin D intake may not reflect vitamin D status, as circulating concentrations of 25-hydroxyvitamin D depend largely on sun exposure ${ }^{(4)}$. Higher $\mathrm{K}$ intakes are a known protective factor for hypertension ${ }^{(30)}$, whereas excessive $\mathrm{Na}$ intake is an established risk factor for hypertension in older adults ${ }^{(31)}$. In our study, only a fifth of the participants were below the RNI of $1600 \mathrm{mg} / \mathrm{d}$ of $\mathrm{Na}$ but half of them met the recommendation of $<2400 \mathrm{mg} / \mathrm{d}$. Na intake reduction and increased $\mathrm{K}$ intake might help reduce the prevalence of stroke and fatal CHD in this population ${ }^{(32)}$.

More than $10 \%$ of participants had vitamin A intakes below the LRNI but, interestingly, $5 \%$ had intakes above the UL of $3000 \mu \mathrm{g}-\mathrm{RE} / \mathrm{d}$ set by the European Food Safety Authority ${ }^{(33)}$. This classic paradox may not be the result of habitual intake, but the result of consuming high vitamin A-containing foods (e.g. liver and liver dishes) on one or more of the nonconsecutive $24-\mathrm{h}$ recalls of the $24 \mathrm{~h}-\mathrm{MPR}^{(34)}$. In fact, thirty-five out of the thirty-six participants who had vitamin A intakes above the UL of $3000 \mu \mathrm{g}-\mathrm{RE}$ ate liver and liver products at least on one of the $24 \mathrm{~h}-\mathrm{MPR}$.

Assessing micronutrient intake inadequacies in this age group has several methodological limitations. Among all, $27 \%$ ( $n$ 214) of the participants were classified as cognitively impaired (Standardized Mini-Mental State Examination $\leq 25$ ) (data not shown), which might have played a major part in misreporting (estimated to be $26.3 \%$ ). Further, because of a scarcity of nutrition data in this age group, most DRV were extrapolated from younger populations. This leads to uncertainty regarding the health significance of inadequacies in the very old.

In line with previous studies ${ }^{(35)}$ and a recent review on socioeconomic determinants of micronutrient intakes in older adults $^{(36)}$, participants with more education and from a higher social class had overall higher micronutrient intakes. Similarly, perhaps because healthy habits cluster together, those who were more physically active had more nutrient-dense diets. It has been argued that nutrient-dense foods are more expensive than less-healthy foods in the UK and $\mathrm{USA}^{(37,38)}$, and this price differential might explain the difference in nutrient density between lower and higher socio-economic status (SES) groups. However, others have challenged the view that healthier foods or dietary patterns are more expensive than unhealthy ones and, for example, price differentials are dependent on the unit of comparison (e.g. per unit of energy, per unit of mass) ${ }^{(39,40)}$. Physical proximity to (and/or means to access) fresh-produce stores has been proposed as an explanation for higher micronutrient intakes in high SES groups ${ }^{(41)}$ but this is somewhat debatable in the UK and North-East England ${ }^{(42)}$. Inaccessibility to fresh produce, higher cost of nutrient-dense foods in the UK and poorer food choices ${ }^{(43)}$ are some of the potential causes that mediate the diet quality gradient between SES groups. In this age group, with more disabilities and lower income, these issues might be exacerbated.

\section{Strengths and weaknesses}

The Newcastle $85+$ Study was socio-demographically representative of the general UK population. However, all participants were from Newcastle upon Tyne and North Tyneside and of a predominantly white background, which can limit generalisations ${ }^{(16)}$. We performed $35 \%$ of the 24-h-recalls during summer (June-August), whereas the rest were evenly 
distributed throughout the other three seasons. Seasonality is known to influence micronutrient intakes, but the slight bias towards summer is unlikely to have changed the results. Although vitamins and minerals are not abundantly present in commonly under-reported foods such as sweets and snacks, the inherent retrospective nature of the $24 \mathrm{~h}$-MPR might have proved challenging for some individuals in this age group. Adamson et al. ${ }^{(44)}$ have described in detail the challenges of dietary assessment in this age group and in the pilot study. To reduce patient and interviewer burden, only qualitative data on supplement use were collected. Therefore, the frequency of supplement use had to be estimated on the basis of the manufacturer's recommendations. Data on Na derived from table salt and salt used in cooking were not recorded, which might have underestimated $\mathrm{Na}$ intake in the Newcastle 85+ Study.

\section{Conclusion}

Food sources of the selected micronutrients in the Newcastle 85+ Study were diverse; however, as CCP were widely consumed, they were among the top contributors to intakes of several vitamins and minerals. Higher SES and greater physical activity were associated with higher micronutrient intakes. Compared with current DRV, several micronutrient intakes were 'inadequate' and Se $(52.7 \%$ below the LRNI) and vitamin D $(95.3 \%$ below the $\mathrm{RNI})$ showed the greatest disparities. However, the lack of evidence-based, age-specific DRV for micronutrients for the very old means that such information should be interpreted with caution. As energy requirements are dependent on energy expenditure, the decrease in energy needs in later life mirrors the age-dependent fall in physical activity. However, the physiological basis for age-dependent changes in vitamin and mineral requirements (if any) is poorly understood. In the absence of such evidence, it may be appropriate that dietary information for very old people focuses on healthy food choices, on increasing nutrient density and only recommending the use of supplements in specific situations $^{(45)}$.

In summary, this study provides novel insights into micronutrient intakes, their corresponding food sources and the socio-demographic and lifestyle determinants of micronutrient intakes in very old people. Given the dearth of dietary intake data in the very old, the contemporary micronutrient data from our study are likely to be the most reliable for this age group in the UK. These findings need to be confirmed in other cohort studies of the very old.

\section{Acknowledgements}

The authors acknowledge the operational support of the North of England Commissioning Support Unit (formerly NHS North of Tyne) and of the local general practitioners and their staff. The authors thank Professor Tim Key and Dr Paul Appleby for providing dietary data on the EPIC-Oxford for comparison purposes. The authors also thank the research nurses, dietary coders, management and clerical team for outstanding work throughout, as well as many colleagues for their expert advice.
Thanks are due especially to the study participants and, where appropriate, their families and carers.

The Newcastle $85+$ Study has been funded by the Medical Research Council, Biotechnology and Biological Sciences Research Council and the Dunhill Medical Trust. The research was also supported by the National Institute for Health Research (NIHR), Newcastle Biomedical Research Centre, based at Newcastle upon Tyne Hospitals, NHS Foundation Trust and Newcastle University. A. J. A. is funded by the NIHR as a Professor in translational research.

The authors' contributions to the study were as follows: N. M., T. R. H., C. J. S. and C. J. designed the study, N. M. analysed the data, performed statistical analyses and wrote the paper, T. B. L. K. is the principal investigator on the Newcastle $85+$ Study. All authors contributed to the interpretation of the findings of the study, read, critically reviewed the manuscript, commented and approved the final version of the manuscript.

None of the authors reported any conflicts of interest.

\section{Supplementary material}

For supplementary material/s referred to in this article, please visit http://dx.doi.org/10.1017/S0007114516002567

\section{References}

1. Johnson MA (2007) If high folic acid aggravates vitamin $B_{12}$ deficiency what should be done about it? Nutr Rev 65 , 451-458.

2. Hughes CF, Ward M, Hoey L, et al. (2013) Vitamin $\mathrm{B}_{12}$ and ageing: current issues and interaction with folate. Ann Clin Biochem 50, 315-329.

3. Russell RM (2001) Factors in aging that effect the bioavailability of nutrients. J Nutr 131, 1359s-1361s.

4. Hill TR, Aspray TJ \& Francis RM (2013) Vitamin D and bone health outcomes in older age. Proc Nutr Soc 72, 372-380.

5. Inzitari M, Doets E, Bartali B, et al. (2011) Nutrition in the agerelated disablement process. J Nutr Health Aging 15, 599-604.

6. Department of Health: Committee on Medical Aspects of Food Policy (COMA) (1991) Report on Health and Social Subjects 41: Dietary Reference Values for Food Energy and Nutrients for the United Kingdom. London: The Stationery Office.

7. McCormick DB (2012) Vitamin/trace mineral supplements for the elderly. Adv Nutr 3, 822-824.

8. Bates CJ, Prentice A, Cole TJ, et al. (1999) Micronutrients: highlights and research challenges from the 1994-5 National Diet and Nutrition Survey of people aged 65 years and over. Br J Nutr 82, 7-15.

9. Roman Vinas B, Ribas Barba L, Ngo J, et al. (2011) Projected prevalence of inadequate nutrient intakes in Europe. Ann Nutr Metab 59, 84-95.

10. Ter Borg S, Verlaan S, Hemsworth J, et al. (2015) Micronutrient intakes and potential inadequacies of communitydwelling older adults: a systematic review. $\mathrm{Br} J$ Nutr $\mathbf{1 1 3}$, 1195-1206

11. Collerton J, Davies K, Jagger C, et al. (2009) Health and disease in 85 year olds: baseline findings from the Newcastle $85+$ cohort study. BMJ 339, b4904.

12. Collerton J, Barrass K, Bond J, et al. (2007) The Newcastle 85+study: biological, clinical and psychosocial factors associated with healthy ageing: study protocol. BMC Geriatr 7, 14 . 
13. Davies K, Kingston A, Robinson L, et al. (2014) Improving retention of very old participants in longitudinal research: experiences from the Newcastle 85+ Study. PLOS ONE 9, e108370.

14. Nelson M, Atkinson M \& Meyer J (1997) A Photographic Atlas of Food Portion Sizes. London: Ministry of Agriculture, Fisheries and Farming (MAFF) Publications.

15. Food Standards Agency (2002) McCance and Widdowson's the Composition of Foods, 6th summary edition. Cambridge, MA: Royal Society of Chemistry.

16. Mendonça N, Hill TR, Granic A, et al. (2016) Macronutrient intake and food sources in the very old: analysis of the Newcastle 85+ Study. Br J Nutr 115, 2170-2180.

17. Chandola T \& Jenkinson C (2000) The new UK National Statistics Socio-Economic Classification (NS-SEC); investigating social class differences in self-reported health status. J Public Health Med 22, 182-190.

18. Innerd P, Catt M, Collerton J, et al. (2015) A comparison of subjective and objective measures of physical activity from the Newcastle 85+ study. Age Ageing 44, 691-694.

19. Finch S, Doyle W, Lowe C, et al. (1998) National Diet and Nutrition Survey: People Aged 65 Years and Over - Report of the Diet and Nutrition Survey. London: The Stationery Office.

20. European Prospective Investigation of Cancer (2015) The EPIC-Oxford Study. http://www.epic-oxford.org/ (accessed January 2015).

21. Bates B, Lennox A, Prentice A, et al. (2014) National diet and nutrition survey years 1-4 (combined) (2008/2009-2010/12) appendices and tables. https://www.gov.uk/government/ statistics/national-diet-and-nutrition-survey-results-from-years1-to-4-combined-of-the-rolling-programme-for-2008-and-2009to-2011-and-2012 (accessed August 2015).

22. Scientific Advisory Committee on Nutrition (SACN) (2015) Draft Vitamin D and Health Report. https://www.gov.uk/ government/uploads/system/uploads/attachment_data/file/ 447402/Draft_SACN_Vitamin_D_and_Health_Report.pdf. (accessed March 2015).

23. Veronese N, Berton L, Carraro S, et al. (2014) Effect of oral magnesium supplementation on physical performance in healthy elderly women involved in a weekly exercise program: a randomized controlled trial. Am J Clin Nutr 100, 974-981.

24. Chacko SA, Song Y, Nathan L, et al. (2010) Relations of dietary magnesium intake to biomarkers of inflammation and endothelial dysfunction in an ethnically diverse cohort of postmenopausal women. Diabetes Care 33, 304-310.

25. Orchard TS, Larson JC, Alghothani N, et al. (2014) Magnesium intake, bone mineral density, and fractures: results from the Women's Health Initiative Observational Study. Am J Clin Nutr 99, 926-933.

26. Semba RD, Ricks MO, Ferrucci L, et al. (2009) Low serum selenium is associated with anemia among older adults in the United States. Eur J Clin Nutr 63, 93-99.

27. Ray AL, Semba RD, Walston J, et al. (2006) Low serum selenium and total carotenoids predict mortality among older women living in the community: the women's health and aging studies. J Nutr 136, 172-176.

28. Granic A, Aspray T, Hill T, et al. (2015) 25-hydroxyvitamin D and increased all-cause mortality in very old women: the Newcastle 85+ study. J Intern Med 277, 456-467.
29. Granic A, Hill TR, Kirkwood TB, et al. (2015) Serum 25-hydroxyvitamin $\mathrm{D}$ and cognitive decline in the very old: the Newcastle 85+ Study. Eur J Neurol 22, 106-115; e106-e107.

30. Smith SR, Klotman PE \& Svetkey LP (1992) Potassium chloride lowers blood pressure and causes natriuresis in older patients with hypertension. J Am Soc Nephrol 2, 1302-1309.

31. Alam S \& Johnson AG (1999) A meta-analysis of randomised controlled trials (RCT) among healthy normotensive and essential hypertensive elderly patients to determine the effect of high salt $(\mathrm{NaCl})$ diet of blood pressure. J Hum Hypertens 13, 367-374.

32. Strazzullo P, D'Elia L, Kandala N-B, et al. (2009) Salt intake, stroke, and cardiovascular disease: meta-analysis of prospective studies. BMJ 339, b4567.

33. Scientific Committee on Food, Scientific Panel on Dietetic Products Nutrition and Allergies (2006) Tolerable Upper Intake Levels for Vitamins and Minerals. Parma: European Food Safety Authority.

34. Scientific Advisory Committee on Nutrition (SACN) (2005) Review of Dietary Advice on Vitamin A. London: The Stationery Office.

35. Darmon N \& Drewnowski A (2008) Does social class predict diet quality? Am J Clin Nutr 87, 1107-1117.

36. Novakovic R, Cavelaars A, Geelen A, et al. (2014) Socioeconomic determinants of micronutrient intake and status in Europe: a systematic review. Public Health Nutr 17, 1031-1045.

37. Jones NR, Conklin AI, Suhrcke M, et al. (2014) The growing price gap between more and less healthy foods: analysis of a novel longitudinal UK dataset. PLOS ONE 9, e109343.

38. Aggarwal A, Monsivais P, Cook AJ, et al. (2011) Does diet cost mediate the relation between socioeconomic position and diet quality? Eur J Clin Nutr 65, 1059-1066.

39. Rao M, Afshin A, Singh G, et al. (2013) Do healthier foods and diet patterns cost more than less healthy options? A systematic review and meta-analysis. BMJ Open 3, e004277.

40. Carlson A \& Frazão E (2012) Are Healthy Foods Really More Expensive? It Depends on How You Measure the Price. EIB-96. Washington, DC: US Department of Agriculture, Economic Research Service.

41. Bodor JN, Rose D, Farley TA, et al. (2008) Neighbourhood fruit and vegetable availability and consumption: the role of small food stores in an urban environment. Public Health Nutr 11, 413-420.

42. Cummins S \& Macintyre S (2002) 'Food deserts' - evidence and assumption in health policy making. BMJ 325, 436-438.

43. McKinnon L, Giskes K \& Turrell G (2014) The contribution of three components of nutrition knowledge to socio-economic differences in food purchasing choices. Public Health Nutr 17, 1814-1824.

44. Adamson AJ, Collerton J, Davies K, et al. (2009) Nutrition in advanced age: dietary assessment in the Newcastle 85+ study. Eur J Clin Nutr 63, Suppl. 1, S6-S18.

45. World Cancer Research Fund \& American Institute for Cancer Research (2007) Food, Nutrition, Physical Activity, and the Prevention of Cancer: a Global Perspective. Washington, DC: AICR. 